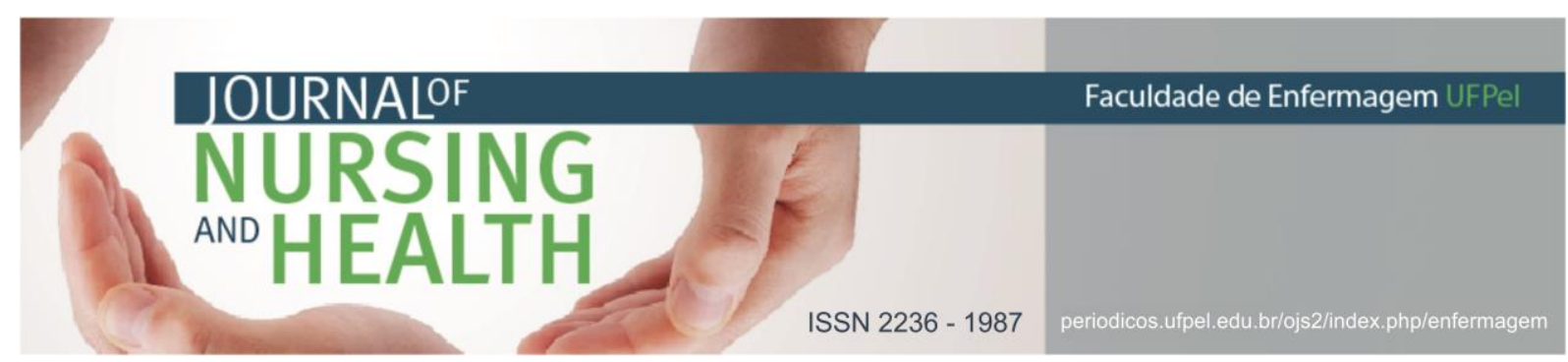

DEPOIMENTOS DOS EXPERTS POR EXPERIÊNCIA

\title{
Da experiência de ouvir vozes: não estamos sozinhos(as)!
}

From the experience of hearing voices: we are not alone!

De la experiencia de oír voces: ¡no estamos solos!

Ubessi, Liamara Denise1; Lemões, Marcos Aurélio Matos²; Machado, Roberta Antunes³; Bender , Andrea Regina Molina Jaekel ${ }^{4}$; Lopes , Ivon Fernandes ${ }^{5}$; Zacaria, Carlos Alberto Narciso ${ }^{6}$; Jardim, Vanda Maria da Rosa ${ }^{7}$

Como citar este artigo: Ubessi LD, Lemões MAM, Machado RA, Bender ARMJ, Lopes IF, Zacaria CAN, et al. J. nurs. health. 2018;8(n.esp.):e188411

Palavras-chave: Saúde mental; Ouvir vozes; Experiências.

\section{APRESENTAÇÃO}

Somos muitas vozes. São muitas as vozes. Vozes que se manifestam de distintas formas. E somos loucos/as por ouvir vozes? Pensamos que não. Que somos pessoas como qualquer pessoa, com particularidades. No nosso caso, de ouvir vozes, assim como outras pessoas podem ter as suas.

Entendemos que a loucura foi subtraída da sua potência, quando fora designada como doença. Saberes e poderes assim a definiram, escrutinando características, sinais e sintomas ${ }^{1}$. Por exemplo, 'ouvir vozes' era um dos sintomas dessa 'doença'.

E a cura seria banir esse sintoma, o que foi e ainda é feito com o uso de drogas psicotrópicas, sem ao menos indagar a pessoa sobre as (suas) vozes, conteúdo, ocorrência, como são, o que dizem, qual o sentido para si, entre outras coisas, para que juntos(as) se construam sentidos a essa experiência de ouvir vozes, em que a

\footnotetext{
1 Graduada em Psicologia e Enfermagem. Doutora em Ciências. Universidade Federal de Pelotas. E-mail: liaubessi@gmail.com https://orcid.org/0000-0002-5884-9969

2 Enfermeiro. Doutor em Ciências. Universidade Federal de Pelotas. E-mail: enf.lemoes@gmail.com http://orcid.org/0000-0002-6897-4130

${ }^{3}$ Enfermeira. Mestre em Ciências. Instituto Federal de Educação, Ciência e Tecnologia do Rio Grande do Sul (IFRS). E-mail:roberta.machado@riogrande.ifrs.edu.br http://orcid.org/0000-0002-9087-6457

${ }^{4}$ Agricultura e artesã. Usuária do Centro de Atenção Psicossocial Escola. Integrante da Associação de Usuários dos Serviços de Saúde Mental de Pelotas (AUMSSPE). E-mail: andreabender52@gmail.com https: //orcid.org/00000001-8622-503X

5 Acadêmico de Serviço Social. Universidade Católica de Pelotas. E-mail: ivonlopesnaval@hotmail.com http: / /orcid.org/0000-0003-3182-9113

${ }^{6}$ Integrante do Grupo Vocal Esperança, do Musical Los Lokos e da Associação de Usuários dos Serviços de Saúde Mental de Pelotas (AUMSSPE). E-mail: carloszacaria8@gmail.com http://orcid.org/0000-0001-6302-3320

7 Enfermeira. Doutora em Enfermagem. Universidade Federal de Pelotas. E-mail: vandamrjardim@gmail.com http: / /orcid.org/0000-0001-8320-4321
} 


\section{NURSING \\ AND

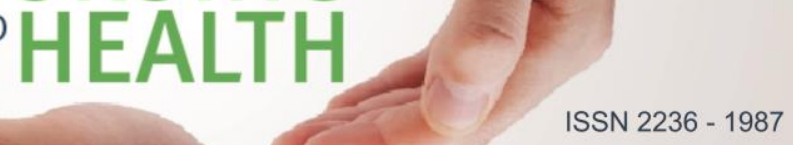

medicação não precisaria ser a única possibilidade, ou nem figurar neste rol de possibilidades.

Nós mesmos, seja pelos nossos relatos e também o movimento de Ouvidores de Vozes tem contribuído para que nos libertássemos de nossos aprisionamentos subjetivos, seja quem ouve vozes e quem não ouve, e estabelecermos novas relações com as nossas vozes, com quem ouve vozes, compreendendo que não somos os(as) loucos(as) dessa loucura estigmatizada, que somos cidadãos(ãs) que ouvem vozes, mas que não somos mais ou menos que ninguém por isso.

Deste modo, apresentamos um pouco de nossas experiências compartilhadas com pessoas que não ouvem vozes, mas que são engajadas na luta por uma outra loucura, de sermos aceitos do jeito que somos, tratados(as) com dignidade, sem que nossa vida seja, ou pelo fato de ouvirmos vozes, seja "patologizada", "medicalizada", "medicamentalizada".

Então, juntos(as), sistematizamos e narramos aspectos de nossa experiência com as vozes, para que outras pessoas conheçam, se empoderem a falar de suas experiências com as vozes, produzam outra relação com as mesmas e se somam na luta contra o preconceito, estigmatização e violação de direitos, que muitos de nós e outras pessoas que ouvem vozes, sofreram e ainda sofrem no curso da história da humanidade ${ }^{2}$.

\section{Compartilhando nossa conversa com Aiyra Terra}

Quando indagada sobre ouvir vozes, Aiyra Terra nos surpreende:

"Sempre! Desde muito pequena. Só que na minha infância achava que todo mundo ouvia vozes. Que era de todo e qualquer humano ouvir vozes. Não falava sobre as vozes com ninguém, pois justamente achava que todos ouviam. E isso para mim era normal".

Os sentidos fazem parte de nossa conexão com o mundo e, desta forma nos diferentes ciclos vitais, vamos afinando estas vinculações com maior ou menor estabilidade, ao ponto de percebemos a realidade de nosso entorno ${ }^{2}$. Por outro lado, alguns de nós têm a capacidade de perceber em nossas vivências que o óbvio não é para todos, ao concluir que ouvir vozes de certo modo nos distancia de uma realidade socialmente permitida até então.

Foi assim que Aiyra Terra que compõe conosco coletivos de movimentos sociais e no campo da saúde mental e coletiva e na Associação de Usuários(as) dos Serviços de Saúde Mental de Pelotas (AUSSMPE) dialogou conosco sua narrativa. Uma ouvidora de voz no seu cotidiano e, que aos poucos em seus ciclos vitais foi percebendo o quão sofrido, desafiador e complexo é essa composição com a realidade.

Aiyra Terra nos relata:

"Que quem ouvia vozes era considerado como louco. Havia muitas brincadeiras, do tipo, 'vai para o hospício', lugar de louco é no hospício. Aí, percebi que se 


\section{JOURNALOF

contasse que ouvia vozes, que via coisas, como visões de acontecimentos futuros, de vultos, sensações, cheiros, era coisa de louco, boba eu de contar que ouvia vozes. Nunca! Primeiro, não achava que era louca. Estou falando dessa loucura do estigma, estigmatizada, pois para mim a loucura tem outro sentido. Segundo, eu não queria ir para um manicômio por ouvir vozes. Apenas contava para algumas pessoas das visões que tinha e mesmo assim, as pessoas já me olhavam estranho. Então, fui guardando isso comigo. Houve uma situação que o desespero foi grande. Sentia as vozes por cheiros. E comecei a querer explicação. Vaguei mundo como se diz, e as explicações não me satisfaziam. Meio que desisti de procurar".

Ao passar para outro estágio de sua vivência compreendeu que não era tão simples assim ser uma ouvidora de vozes e que a sociedade já tinha alguns preceitos que distinguem o que se apresenta fora da normalidade estabelecida. A adolescência não é uma fase simples e a aceitação social é um componente especialmente importante.

Ao perguntamos como eram suas vozes, Aiyra Terra nos diz que:

"[...]são de diversas formas, jeitos. Estão sempre comigo. Sempre, sempre.

Ultimamente andam em cochicho. Em alguns momentos uma ou outra conversa comigo. Mas geralmente estão conversando entre elas. Não entendo nada que dizem. Só entendo quando uma ou outra conversa comigo".

Nesse cotidiano, Terra foi se constituído com as vozes e, mesmo estando presentes as vozes nem sempre a acionam. Ela nos descreve que nas situações de angústias, medos e de opressão, as vozes dialogam com maior frequência.

Assim resolvemos perguntar como ela interpreta as suas vozes. Aiyra Terra as explica de dois modos:

"Um deles, é que sou eu mesma. Variação de mim mesma. Jeito de defesa ante o viver. $O$ mais lindo da subjetividade de alguém. Claro, que muitas vezes não são 'flores'. Hoje, posso dizer que a maioria delas são minhas companheiras. Minha maior dor sempre foi a solidão. Tive que cuidar de mim mesma desde muito cedo. Todos temos, né?! Às vezes tenho medo é de mim mesma, de ficar sozinha comigo mesma. Mas, hoje elas estão aí como companhia. Outra explicação, é que devido alguns ou muitos acontecimentos na vida, há um elemento de energias, que algumas pessoas denominariam como espiritualidade. Essa explicação é aceita no movimento de ouvidores(as), mas ainda sinto que há preconceitos em relação a isso, mesmo que faça sentido a quem ouve e explica o ouvir vozes nesta relação".

Aiyra Terra faz conexões sobre o seu modo de vida, de seus medos e ciclos e que apesar do progresso dos grupos de ouvidores de vozes, ainda percebe um limite de entendimento que necessita ser considerado, dos não ouvidores em relação aos ouvidores, principalmente no que se refere a espiritualidade e as vozes. A questão de artifícios no convívio com as vozes é pertinente a todos nós que estamos 


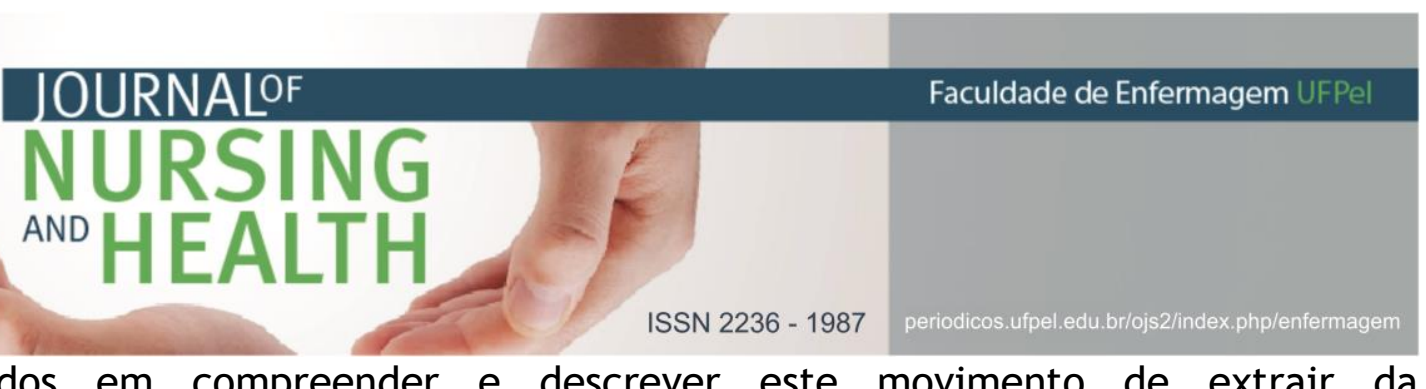

debruçados em compreender e descrever este movimento de extrair da anormalidade, o ser um ouvidor.

Neste dialogo, surge-nos a curiosidade de como Aiyra Terra lida com as vozes, sendo que enunciou que não faz uso de medicação.

"Sempre lidei com elas, não dando bola para elas. Só que houveram momentos que não deu para desconsiderar as mesmas, devido as suas manifestações e ao que me anunciavam e que acaba acontecendo. Então vivi momentos de muita tensão. Por exemplo, as vozes perversas, que dizem coisas que me colocam em xeque como pessoa, como o que sou, penso e faço, procuro relegar a um segundo plano. Com algumas, eu negocio. Faço o que me pedem, por mais esquisito que isso possa parecer. Mas faço, pois não é nada do campo do absurdo. É do que é possível negociar sem danos ou reduzindo danos. E há as de comando. Que insistem. Essas envolvem automutilação. Não consigo explicar, mas enfrento. Como vou dizer, não as obedeço. Espero sempre conseguir enfrentá-las. E nos últimos anos, por me enveredar em diversos coletivos e práticas, comecei a fazer um outro movimento, o de ouvi-las, de considerá-las, e por isso, acho que nossa relação de modo geral, mudou. Vivemos mais em paz! Negociar e enfrentar e aceitar. Isso aprendi, tudo muda. E acho que quando comecei a(me) aceitar com as vozes, tudo foi mudando".

Aiyra Terra nos indica que há momentos de diálogos e monólogos com as vozes, e que há necessidade de enfrentamentos em algumas situações, pois as vozes de comandos podem atentar contra a integridade física. Em outras ocasiões até o silenciar diante destes comandos pode ser uma forma de resposta as vozes.

Houve, em 2016, um evento internacional sobre ouvidores de vozes na capital gaúcha, no qual na maioria de nós participou. Este evento nos ajudou a expor nossa vivência com as vozes. Indagamos para Aiyra Terra como foi este encontro para ela e seu contato com o movimento de Ouvidores(as) de Vozes?

A aproximação com o movimento de ouvidores de vozes, por intermédio do Grupo de pesquisa em saúde mental e coletiva da Universidade Federal de Pelotas, nos possibilitou dialogar sobre as vozes, que até então eram silenciadas em muitos de nós.

\footnotetext{
"Na verdade, não estava nenhum pouco a fim de ir no evento. Estava vivendo momentos de reclusão, de querer ficar na minha, de isolamento [para escrever uma tese]. Mas fui. Resolvi ler alguns textos do movimento de ouvidores e fui a loucura, pois o que eles(as) escreviam ia muito ao encontro do que eu desejava, defendia. E isso foi me ajudando a aceitar que ouvia vozes, a dizer sem vergonha nenhuma que ouvia vozes. E hoje tenho dito por aí, e as reações das pessoas tem sido muito engraçadas. Mas, problema delas. Não tenho mais medo e nem vergonha de dizer que ouço vozes."
} 
E para finalizar perguntamos a Aiyra Terra o que pensa sobre pessoas que ouvem vozes? E ela nos responde:

"Que são normais, assim como eu [muitos risos]. E que loucos do estigma é quem diz que a gente é louco ou louca".

\section{REFERÊNCIAS}

1 Foucault M. Doença mental e psicologia. Rio de Janeiro: Tempo Brasileiro; 1975.

2 Foucault M. História da loucura na idade clássica. São Paulo: Perspectiva; 1978.

3 Papalia DE; Olds, SW. Desenvolvimento Humano. $7^{\circ}$ ed. Porto Alegre: Artmed; 2000.

Data de publicação: 19/09/2018 